\title{
Faktor Yang Mempengaruhi Kinerja Karyawan (Studi Kasus KSO Pertamina EP-Gunung Kampung Minyak.Ltd)
}

\author{
Anggreany Hustia*, Fitantina, Nadia Afrilliana \\ Fakultas Ekonomi dan Bisnis, Manajemen, Universitas Muhammadiyah Palembang, Palembang, Indonesia \\ Email: 1, ${ }^{*}$ reanyhustia1012@gmail.com, ${ }^{2}$ fitantina@gmail.com, ${ }^{3}$ Nadiaafrilliana@ymail.com \\ Email Penulis Korespondensi: reanyhustia1012@gmail.com \\ Submitted: 17/11/2021; Accepted: 26/11/2021; Published: 30/11/2021
}

\begin{abstract}
Abstrak-Beberapa teori mengatakan ada banyak hal yang mempengaruhi kinerja karyawan dalam sebuah perusahaan diantaranya adalah kepuasan karyawan, lingkungan karyawan serta kompensasi yang diberikan kepada karyawan. Adanya penelitian ini dilakukan guna mengetahui apakah faktor-faktor tersebut benar berdampak atau mempengaruhi kinerja para karyawan studi kasus KSO Pertamina EP - Gunung Kampung Minyak. Ltd. Populasi penelitian sebanyak69 karyawan dan dijadikan sampel hanya 59 karyawan, dilakukan dengan menggunakan data primer melalui penyebaran kuesioner yang memuat indikasi atas faktor yang diteliti. Gambaran atas hasil penelitian ini adalah menyatakan bahwa ada pengaruh atas kepuasan kerja serta lingkungan kerja terhadap kinerja karyawan. Sedangkan faktor kompensasi dinyatakan tidak berpengaruh atas kinerja. Sementara untuk hasil secara bersamaan didapat bahwa ketiga faktor yang diteliti dalam penelitian ini memiliki pengaru atas kinerja karyawan.
\end{abstract}

Kata Kunci: Kepuasan Kerja; Lingkungan Kerja; Kompensasi; Kinerja; Manajemen Sumber Daya Manusia

\begin{abstract}
Some theories say there are many things that affect employee performance in a company including employee satisfaction, employee environment and compensation given to employees. The existence of this study was conducted to find out whether these factors actually impacted or affected the performance of the employees of the KSO Pertamina EP - Gunung Kampung Minyak case study. Ltd. The studied population of 69 employees and sampled only 59 employees, was conducted used primary data through the dissemination of questionnaires that contained indications of the factors studied. The picture of the resulted of this studied was to state that there was an influenced on job satisfaction and the worked environment on employee performanced. While the compensation factor was declared to had no effect on performanced. While for the resulted simultaneously obtained that the three factors studied in this studied had a confectioner over employee performanced.
\end{abstract}

Keywords: Job Satisfaction; Work Environment; Compensation; Performance; Human Resource Management

\section{PENDAHULUAN}

Sumber daya manusia yang berkompeten dan berintegritas dalam bidang pekerjaannya sangatlah penting guna mewujudkan tujuan organisasi. Hal ini membentuk karakter dalam perusahaan yang mengarahkan pada pembentukkan nilai kinerja karyawan sebagai hasil dari pelaksanaan pekerjaan karyawan diperusahaan yang akan berdampak baiknya tingkat produktifitas perusahaan dan tercapainya tujuan yang telah ditentukan perusahaan. Kinerja karyawan merupakan gambaran akhir hasil pelaksanaan kerja karyawan dalam suatu organisasi secara individu atau kelompok, yang berlandaskan pemberian wewenang serta tanggung jawab dengan tujuan pencapaian visi, misi, dan tujuan perusahaan melalui kemandirian, ketekunan, serta kemampuan menyelasaikan permasalahan berdasarkan ketetapan waktu yang ditentukan melalui tindakan sesuai moral dan etika dengan cara legal dan tidak melanggar hukum (Busro, 2018).

Dalam penilaian kinerja terdapat beberapa faktor-faktor yang dapat mempengaruhi kinerja karyawan yaitu kepuasan kerja, lingkungan kerja dan kompensasi. Pada dasarnya kepuasan kerja ini berasal dari perasaan seorang karyawan yang akhirnya menunjukkan cara karyawan tersebut bersikap dalam pekerjaannnya. Karyawan yang memiliki perasaan positif atas keadaan dalam perusahaan akan menunjukkan rasa senang maka ia akan dapat berperan serta maksimal dalam mencapai tujuan perusahaan dan sebaliknya perasaan negatif atas keadaan dalam perusahaan akan menunjukkan rasa yang tidak senang akan berdampak pada rendahnya kinerja yang dihasilkan oleh karyawan tersebut. Sikap yang menunjukkan rasa senang dalam bekerja biasanya disebabkan oleh adanya kepuasan yang didapat dalam bekerja. Dengan demikian sangatlah penting bagi perusahaan yang ingin mencapai maksimalnya tujuan dan mengembangkan usahanya untuk dapat memperhatikan perasaan dari karyawannya melalui terciptanya kepuasan kerja karyawan. Selain dari kepuasan kerja, hal lain yang juga dapat meningkatkan hasil dari pekerjaan karyawaan adalah situasi lingkungan kerja karyawan. Baiknya kondisi dalam lingkungan pekerjaan karyawan akan menciptakan kenyamanan bagi karyawan dalam mengerjakan semua tugas yang diberikan kepadanya. Kemudian jika didukung dengan adanya kesesuaian dan ketepatan dalam pemberian kompensasi atas pekerjaan para karyawan tentunya akan membuat karyawan itu dengan suka rela melakukan pekerjaan yang dibebankan padanya. Dengan demikian apabila lingkungan yang baik tercipta dan kompensasi sesuai serta menimbulkan rasa puas bagi karyawan maka pencapaian tujuan yang diinginkan perusahaan akan terlaksana dengan mudah dan baik sesuai harapan para manajer, pimpinan perusahaan serta stakeholder perusahaan.

Penelitian ini searah dan sejalan dengan beberapa penelitian yang pernah dilakukan dan dipublikasikan sebelumya yang telah meneliti kaitan dari kepuasan kerja, lingkungan kerja dan kompensasi. Beberapa penelitan tersebut yaitu penelitian (Ika Nur Cahyaningrum, 2019) yang melakukan analisis tentang pengaruh kompensasi dan lingkungan kerja terhadap kinerja karyawan melalui kepuasan kerja sebagai variabel intervening studi pada karyawan PT. Sempurna Kuningan Juwana, di Kabupaten Pati, dimana hasil penelitiannya mengatakan adanya pengaruh positif secara signifikan kompensasi dan lingkungan kerja terhadap kinerja karyawan dengan kepuasan kerja sebagai variabel intervening. 
Penelitian selanjutnya adalah (A.Hidayat, 2018) yang melakukan penelitian tentang pengaruh kompensasi dan lingkungan kerja terhadap kinerja Pegawai Dinas Pekerjaan Umum Kota Cilegon dengan kepuasan kerja sebagai variabel intervening, dimana ditemukan bahwa kompensasi dan lingkungan kerja berpengaruh signifikan terhadap kepuasan kerja pegawai dimana semakin baik kompensasi dan lingkungan kerja yang diterima oleh seorang pegawai, makaakan semakin baikpula kepuasan kerjanya. Dan kompensasi berpengaruh signifikan terhadap kinerja karyawan, sementara lingkungan kerja tidak berpengaruh terhadap kinerja karyawan. Penelitian (Hasanuddin et al., 2020) Pengaruh budaya organisasi, kompensasi, dan lingkungan kerja terhadap kinerja pegawai dengan kepuasaan kerja sebagai variabel intervening (Kantor Bappeda Kabupaten Bima NTB) dimana hasil penelitian menyatakan bahwa kompensasi dan lingkungan kerja dengan dimediasi oleh kepuasan kerja berpengaruh positif dan signifikan terhadap kinerja karyawan.

Dalam penelitian ini yang dilakukan pada pada KSO Pertamina EP Objek penelitian adalah KSO Pertamina EP Gunung Kampung Minyak. Ltd. yaitu sebuah perusahaan yang melakukan kegiatan operasi minyak dan gas yang dalam kegiatannya perusahaan ini melakukan Kerja Sama Operasi (KSO) antara PT Gunung Kampung Minyak Ltd dengan PT Pertamina EP. Melalui penelitian yang dilakukan ini ditujukan agar perusahaan faktor-faktor yang diteliti atas kinerja ini dapat dijadikan perhatian sehingga perusahaan dapat lebih meningkatkan dan memaksimalkan hasil produksi perusahaan.

\section{METODE PENELITIAN}

\subsection{Kerangka Dasar Penelitian}

Penelitian asosiatif digunakan dalam penelitian ini dengan tujuan mendapatkan informasi mengenai pengaruh dan hubungan antara variabel kinerja sebagai variabel independen dengan variabel kepuasan kerja, lingkungan kerja dan kompensasi sebagai variabel dependen. Dalam pelaksanaannya tahapan yang dilakukan peneliti guna mencapai tujuan penelitian agar dapat bermanfaat bagi banyak pihak terutama bagi perusahaan adalah melakukan observasi serta wawancara langsung keperusahaan guna mencari informasi permasalahan dalam perusahaan, melakukan penyebaran kuesioner dengan berlandaskan studi literatur terkait dari varibel atau faktor yang menjadi permasalahan. Observasi dan wawancara dilakukan diawal penelitian guna mengetahui permasalahan perusahaan yang berkaitan dengan pencapaian kinerja. Studi literatur dilakukan sebagai menentu arah dan pembatasan dalam penelitan. Kuesioner digunakan sebagai wadah pencarian informasi dalam pelaksanaan penelitian guna mengetahui pengaruh antar variabel yang diteliti dalam penelitian ini.

\subsection{Literasi Dan Kerangka Pemikiran}

\section{a. Kinerja}

Kinerja disimpulkan dari definisi yang menurut Mangkunegara (2010) yaitu hasil dari pelaksanaan kerja yang digapai oleh karyawan sesuai dengan semua tugas serta tanggung jawab yang dilimpahkan perusahaan kepadanya. Studi literatur mengatakan beberapa faktor yang dapat mempengaruhi tingkatan kinerja karyawan diantaranya adalah kepuasan kerja dan lingkungan kerja (Kasmir, 2016) dan kompensasi (Zami, 2010).

\section{b. Kepuasan Kerja}

Kepuasan kerja merupakan hal yang sulit untuk dapat dijelaskan karena merupakan suatu hal kompleks mengenai eleman dalam pelaksanaan kerja seperti jenis dari pekerjaan bagi karyawan, penghasilan gaji/upah yang diperoleh, pencapaian promosi setiap individu, supervise yang dilakukan kepadanya, rekan kerja disekitar karyawan serta pencapaian hasil kerja keseluruhan (Busro, 2018). Kepuasan kerja ini dipengaruhi berbagai faktor baik psikologi, fisik, sosial maupun finansial. (Daryanto, 2016).

\section{c. Lingkungan Kerja}

Lingkungan dapat digambarkan dari keseluruhan perlengkan dan peralatan yang ada, kondisi sekitar tempat bekerja, metode kerja yang digunakan karyawan, serta bagaimana seseorang atau kelompok mengatur pola kerjanya. Perusahaan yang dapat memperhatikan dan menciptakan lingkungan dan kondisi kerja yang baik akan berdapak pada keinginan bekerja yang tentunya berpengaruh pada semangat karyawan dalam melaksanakan pekerjaannya. Lingkungan kerja ini dipengaruhi oleh lingkungan kerja fisik dan nonfisik. (Sedarmayanti, 2017).

\section{d. Kompensasi}

Kompensasi merupakan semua penghasilan dalam bentuk uang ataupun barang (langsung/tidak langsung) yang diberikan pada karyawan sebagai bentuk imbalan atas semua kegiatan yang dilakukannya bagi perusahaan. kompensasi dipengaruhi beberapa hal yaitu adanya penawaran serta permintaan kerja, adanya kemampuan serta kesediaan perusahaan, adanya Serikat Buruh (Organisasi Karyawan), tingkat produktivitas kerja yang dihasilkan karyawan, pemerintah dengan peraturan dan perundangan yang ada, biaya hidup bagi karyawan, tingkatan posisi jabatan pada karyawan, tingkat pendidikan serta pengalaman kerja karyawan, keadaan perekonomian secara nasional, dan bagaimana jenis serta sifat pekerjaan (Hasibuan, S.P, 2018) 
Tabel 1. Operasionalisasi Variabel

\begin{tabular}{cll}
\hline Variabel & \multicolumn{1}{c}{ Definisi Operasional } & \multicolumn{1}{c}{ Indikator } \\
\hline Kinerja Karyawan & $\begin{array}{l}\text { Hasil kerja karyawan baik dari kualitas } \\
\text { maupun kuantitas sesuai dengan tugas dan } \\
\text { tanggung jawab karyawan }\end{array}$ & $\begin{array}{l}\text { 1. Kuantitas } \\
\text { 2. Kualitas }\end{array}$ \\
$\begin{array}{l}\text { Suatu keadaan yang dirasakan oleh karyawan } \\
\text { yang dapat membuatnya bersemangat dalam } \\
\text { pekerjaannya. }\end{array}$ & $\begin{array}{l}\text { 1. Kemampuan } \\
\text { 2. Kepemimpinan }\end{array}$ \\
$\begin{array}{l}\text { Suatu kondisi dimana karyawan merasa } \\
\text { nyaman dalam melaksanakan pekerjaannya. }\end{array}$ & $\begin{array}{l}\text { 1. Sirkulasi Udara } \\
\left(\mathrm{X}_{2}\right)\end{array}$ \\
$\begin{array}{l}\text { Sejumlah imbalan finansial dan nonfinasial } \\
\text { Kompenan Sesama Rekan } \\
\left(\mathrm{X}_{3}\right)\end{array}$ & $\begin{array}{l}\text { 1. Insentif } \\
\text { umpan diberikan kepada karyawan sebagai }\end{array}$ & 2. Fasilitas Kerja \\
& &
\end{tabular}

Indikator yang digunakan dalam penelitian ini didapat dari hasil observasi dan wawancara atas permasalahan yang terjadi pada objek penelitian, yang kemudian pada pembuatan kuesioner dijadikan sebagai dasar dalam pembuatan setiap item pernyataan disetiap variabel yang diteliti, baik sebagai variabel independen maupun sebagai variabel dependennya.

\section{e. Kerangka Pemikiran}

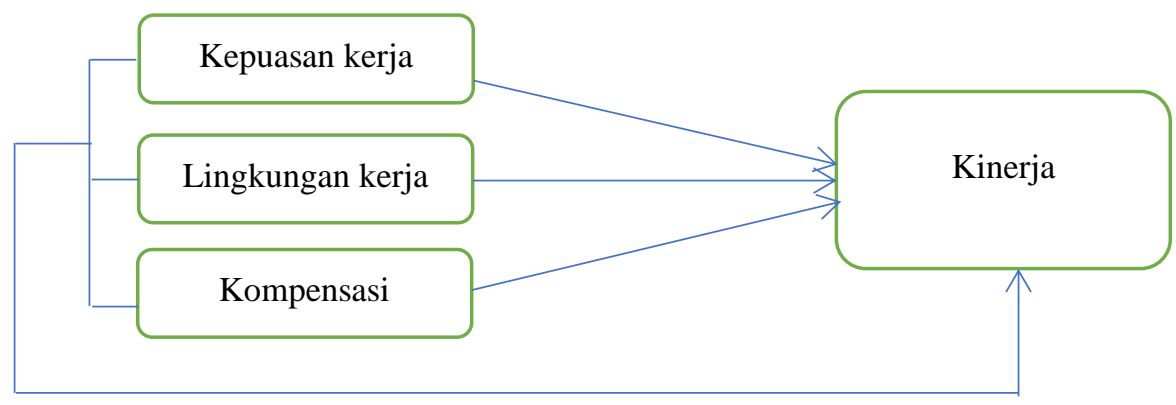

Gambar 1. Kerangka Pemikiran

Gambar dari kerangka pemikiran diatas menjelaskan pelaksanaan penelitian ini tertuju pada pengaruh antara variabel kepuasan kerja atau lingkungan kerja atau kompensasi secara perindividu terhadap variabel kepuasan kerja. Juga tertuju pada pengaruh faktor-faktor kinerja (variabel kepuasan kerja, lingkungan kerja dan kompensasi) terhadap kinerja. Sehinga gambaran atas hipotesi penelitian adalah sebagai berikut:

a. Ada pengaruh kepuasan kerja, lingkungan kerja dan kompensasi terhadap kinerja (Hipotesis 1 )

b. Ada pengaruh kepuasan kerja terhadap kinerja (Hipotesis 2 )

c. Ada pengaruh lingkungan kerja terhadap kinerja $\left(\mathrm{H}_{3}\right)$

d. Ada pengaruh kompensasi terhadap kinerja $\left(\mathrm{H}_{4}\right)$

\section{HASIL DAN PEMBAHASAN}

Dalam upaya mendapatkan hasil sesuai tujuan dari dilakukannya penelitian ini dilakukan pengelolaan data hasil dari penyebaran kuesioner terkait variabel yang diteliti dengan menggunakan alat bantu perhitungan statistik dengan mengunakan aplikasi SPSS versi 25.

\subsection{Uji Instrumen}

Uji Instrumen dalam penelitian ini digunakan sebagai sarana mengetahui kelayakan dan konsistensi jawaban atas item pernyataan dalam kuesioner. Adapun jumlah sampel yang digunakan dalam uji instrument ini adalah sebanyak 30 orang responden.

\subsubsection{Uji Validitas}

Pelaksanaan Uji validitas ditujukan agar dapat menghasilkan kuesioner yang dapat mengungkapkan kondisi permasalahan yang akan diukur serta diteliti dalam penelitian maka sangat dibutuhkan kuesioner yang benar-benar dapat dinyatakan sah atau valid. Hasil uji kevalidan atas variabel-variabel yang diteliti dalam penelitian ini terlihat pada tabel 1. 
Tabel 1. Uji Valliditas

\begin{tabular}{cccc}
\hline $\begin{array}{c}\text { Indikator } \\
\text { variabel }\end{array}$ & $\begin{array}{c}\text { pearson correlation } \\
(\mathrm{r} \text { hitung) }\end{array}$ & $\begin{array}{c}\text { Indikator } \\
\text { variabel }\end{array}$ & $\begin{array}{c}\text { pearson correlation } \\
(\mathrm{r} \text { hitung })\end{array}$ \\
\hline $\mathrm{Y}_{1}$ & 0,437 & $\mathrm{X}_{2.1}$ & 0,584 \\
$\mathrm{Y}_{2}$ & 0,452 & $\mathrm{X}_{2.2}$ & 0,473 \\
$\mathrm{Y}_{3}$ & 0,485 & $\mathrm{X}_{2.3}$ & 0,510 \\
$\mathrm{Y}_{4}$ & 0,407 & $\mathrm{X}_{2.4}$ & 0,692 \\
$\mathrm{Y}_{5}$ & 0,529 & $\mathrm{X}_{2.5}$ & 0,601 \\
$\mathrm{Y}_{6}$ & 0,687 & $\mathrm{X}_{2.6}$ & 0,455 \\
$\mathrm{X}_{1.1}$ & 0,570 & $\mathrm{X}_{3.1}$ & 0,623 \\
$\mathrm{X}_{1.2}$ & 0,479 & $\mathrm{X}_{3.2}$ & 0,451 \\
$\mathrm{X}_{1.3}$ & 0,764 & $\mathrm{X}_{3.3}$ & 0,378 \\
$\mathrm{X}_{1.4}$ & 0,581 & $\mathrm{X}_{3.4}$ & 0,447 \\
$\mathrm{X}_{1.5}$ & 0,395 & $\mathrm{X}_{3.5}$ & 0,606 \\
$\mathrm{X}_{1.6}$ & 0,764 & $\mathrm{X}_{3.6}$ & 0,611 \\
\hline
\end{tabular}

Hasil pearson correlation atas semua variabel yang diteliti bernilai diatas $r$ tabel sebesar 0,361 sehingga dapat dinyatakan bahwa semua item atas indikator faktor-faktor kinerja adalah valid dan dapat dijadikan untuk penelitan lebih lanjut.

\subsubsection{Uji reliabilitas}

Dengan adanya uji reliabilitas maka tingkat konsistensi para responden penelitian dalam menjawab item indikator variabel dalam suatu kuesioner, dikatakan reliable apabila menghasilkan nilai atas cronbanch alpha >0,60. Hasil uji reliabilitas atas variabel-variabel yang diteliti dalam penelitian ini terlihat pada tabel 2 .

Tabel 2. Uji Reliabilitas

\begin{tabular}{lc}
\hline \multicolumn{1}{c}{ Variabel } & Croncbach's Alpha \\
\hline Kinerja Karyawan $(\mathrm{Y})$ & 0,612 \\
Kepuasan Kerja $\left(\mathrm{X}_{1}\right)$ & 0,660 \\
Lingkungan Kerja $\left(\mathrm{X}_{2}\right)$ & 0,633 \\
Kompensasi $\left(\mathrm{X}_{3}\right)$ & 0,682 \\
\hline
\end{tabular}

Hasil Croncbach's Alpha atas semua variabel yang diteliti bernilai diatas sebesar 0,6 sehingga dapat dinyatakan bahwa semua item atas variabel penelitain adalah reliabel dan dapat dijadikan untuk penelitan lebih lanjut.

\subsection{Analisis Regresi Berganda}

Tabel 3. Analisis Regresi Linier Berganda

\begin{tabular}{ccccc}
\hline & & \multicolumn{2}{c}{ Unstandardized Coefficients } & Standardized Coefficients \\
\cline { 3 - 5 } & Model & $\mathrm{B}$ & Std. Error & Beta \\
\hline 1 & (Constant) & 3.433 & 3.990 & \\
& $\mathrm{X}_{1}$ & .444 & .118 & .431 \\
$\mathrm{X}_{2}$ & .289 & .149 & .258 \\
& $\mathrm{X}_{3}$ & .076 & .163 & .063 \\
\hline
\end{tabular}

a. Dependent Variable: kinerja

$$
Y=3,990+0,444 X_{1}+0,289 X_{2}+0.076 X_{3}
$$

Persamaan atas hasil analisis regresi linier berganda menunjukkan beberapa informasi atas hasil penelitian yaitu pertama, dapat dinyatakan bahwa nilai konstanta dalam penelitian bernilai 3,433 (positif), dimana ini menginformasikan bahwa kinerja karyawan akan tetap bernilai sebesar konsatanta yaitu 3,433 meskipun variabel atas faktor-faktor kinerja (variabel kepuasan kerja, lingkungan kerja serta kompensasi) bernilai nol. Kedua, nilai koefisien kepuasan kerja sebesar 0,444 (positif), nilai ini menginformasikan bahwa kepuasan kerja memiliki pengaruh positif atas kinerja karyawan. Peningkatan atas kinerja akan terjadi apabila tingkat kepuasan kerja karyawan yang diberikan perusahaan naik berlaku juga pada kondisi sebaliknya yaitu akan terjadi penurunan kinerja jika tingkat kepuasan karyawan tidak terpenuhi. Ketiga, nilai koefisien lingkungan kerja sebesar 0,286 (positif), nilai ini menginformasikan bahwa lingkungan kerja memiliki pengaruh positif atas kinerja karyawan. Peningkatan atas kinerja akan terjadi apabila tingkat lingkungan kerja karyawan dirasa nyaman bagi karyawan, berlaku juga pada kondisi sebaliknya yaitu akan terjadi penurunan kinerja jika kondisi lingkungan kerja karyawan dirasa tidak nyaman. Ketiga, nilai koefisien kompensasi sebesar 0,076 (positif), nilai ini menginformasikan bahwa kompensasi memiliki pengaruh positif atas kinerja karyawan. Peningkatan atas kinerja akan terjadi apabila tingkat kompensasi yang diberikan kepada karyawan sesuai dengan hasil kerjanya, berlaku juga pada 
kondisi sebaliknya yaitu akan terjadi penurunan kinerja jika kompensasi yang diterima karyawan tidak sesuai dengan segala usaha yang dilakukannya. Keempat, dari ketiga faktor yang diteliti atas kinerja maka terlihat bahwa variabel kepuasan kerja karyawan yang paling berpengaruh dibandingkan variabel yang diteliti lainnya.

\subsection{Uji Hipotesis}

\subsubsection{Uji F (F-test)}

Tabel 4. Uji F

\begin{tabular}{llccccc}
\multicolumn{7}{c}{ ANOVA $^{\mathbf{b}}$} \\
\hline Model & & Sum of Squares & df & Mean Square & F & Sig. \\
\hline 1 & Regression & 106.419 & 3 & 35.473 & 7.557 & $.000^{\mathrm{a}}$ \\
& Residual & 258.157 & 55 & 4.694 & & \\
& Total & 364.576 & 58 & & & \\
\hline
\end{tabular}

a. Predictors: (Constant), kepuasan, lingkungan, kompensasi

b. Dependent Variable: kinerja

Tingkat keyakinan dalam penelitan yaitu 90\% sedangkan tingkat kesalahan sebesar 10\%. Dalam menganalisa uji $\mathrm{F}$ ini akan dibandingkan antara $\mathrm{F}$ hasil dari perhitungan dengan nilai $\mathrm{F}$ yang ada pada tabel F. Derajat kebebasan dalam penelitian ini adalah 55 terlihat dari tabel Uji F sehingga nilai F tabel penelitian sebesar 2,19 dan F hitung sebesar 7,557.

\subsubsection{Uji t (t-test)}

Tabel 5. Uji t

Coefficients $^{\mathrm{a}}$

\begin{tabular}{|c|c|c|c|c|c|c|}
\hline & \multirow[b]{2}{*}{ Model } & \multicolumn{2}{|c|}{ Unstandardized Coefficients } & \multirow{2}{*}{$\frac{\text { Standardized Coefficients }}{\text { Beta }}$} & \multirow[b]{2}{*}{$\mathrm{t}$} & \multirow[b]{2}{*}{ Sig. } \\
\hline & & $\mathrm{B}$ & Std. Error & & & \\
\hline \multirow[t]{4}{*}{1} & (Constant) & 3.433 & 3.990 & & .860 & .393 \\
\hline & $\mathrm{X}_{1}$ & .444 & .118 & .431 & 3.752 & .000 \\
\hline & $\mathrm{X}_{2}$ & .289 & .149 & .258 & 1.932 & .059 \\
\hline & $\mathrm{X}_{3}$ & .076 & .163 & .063 & .465 & .644 \\
\hline
\end{tabular}

a. Dependent Variable: kinerja

Dalam menganalisa uji t ini akan dibandingkan antara t hasil dari perhitungan dengan nilai t yang ada pada tabel t. nilai t tabel penelitian sebesar 1,673. Dari tabel dinyatakan bahwa nilai t hitung kepuasan kerja sebesar 3,752, lingkungan kerja sebesar1,932 dan kompensasi sebesar 0,465.

\subsection{Hasil Hipotesis}

Dari hasil analisis atas data yang diperoleh berkaitan dengan variabel yang diteliti didapatlah hasil hipotesisnya yaitu;

a. Pengaruh Kepuasan Kerja, Lingkungan Kerja Dan Kompensasi Terhadap Kinerja $\left(\mathrm{H}_{1}\right)$

Perbandingan antara Fhitung denga Ftabel yaitu 7,557 > 2,19 dan perbadingan tingkat signifikansi Fhitung dengan tingkat kesalahan yang ditatapkan yaitu $0,000<0,1$ (signifikan). Dari hasil Fhitung dan signifikansi uji $\mathrm{F}$ maka dinyatakan bahwa Hipotesis $\mathrm{H}_{0}$ ditolak $\mathrm{H}_{\mathrm{a}}$ diterima yaitu antara variabel faktor-faktor yang mempengaruhi kinerja yang diteliti yaitu variabel kepuasan kerja, lingkungan kerja dan kompensasi memiliki pengaruh atas kinerja karyawan. Dengan demikian Hipotesis penelitian $\mathrm{H}_{1}$ terbukti.

b. Pengaruh Kepuasan Kerja Terhadap Kinerja $\left(\mathbf{H}_{2}\right)$

Hasil uji t hitung atas variabel kepuasan kerja terlihat dari tabel bernilai 3,752 sedangkan signifikansinya 0,000 ini artinya $t$ hitung bernilai lebih besar jika diperbandingkan dengan t tabel yaitu 3,752>1,673 sedangkan dari sisi signifikansinya $0,000<0,100$ yang menandakan variabel dari faktor kepuasan kerja berpengaruh signifikan atas kinerja karyawan hipotesisnya $\mathrm{H}_{0}$ ditolak $\mathrm{H}_{\mathrm{a}}$ diterima dengan demikian hipotesis penelitian $\mathrm{H}_{2}$ terbukti.

Hal ini sejalan dengan teori (Kasmir., 2016) bahwa lingkungan kerja merupakan faktor yang dapat mempengaruhi kinerja karyawan. Selain itu juga sejalan dengan penelitian yang dilakukan oleh (Ika Nur Cahyaningrum, 2019), (Wijaya, 2018), (Tjiong Fei Lie, 2018), (Fitrianto, 2020) dengan hasil yang membuktikan kinerja karyawan dipengaruhi faktor kepuasan kerja. Dengan Hasil yang sejalan tersebut maka KSO Pertamina EP-Gunung Kampung Minyak perlu memperhatikan kepuasan karyawan dalam perusahaan sehingga karyawan tersebut dapat meningkatkan kinerjanya dan tujuan perusahaan dapt tercapai maksimal.

c. Pengaruh Lingkungan Kerja Terhadap Kinerja $\left(\mathbf{H}_{3}\right)$

Hasil uji t hitung atas variabel lingkungan kerja terlihat dari tabel bernilai 1,932 sedangkan signifikansinya 0,059 ini artinya t hitung bernilai lebih besar jika diperbandingkan dengan t tabel yaitu 1,932>1,673 sedangkan dari sisi 
signifikansinya $0,059<0,100$ yang menandakan variabel dari faktor lingkungan kerja berpengaruh signifikan atas kinerja karyawan hipotesisnya $\mathrm{H}_{0}$ ditolak $\mathrm{H}_{\mathrm{a}}$ diterima dengan demikian hipotesis penelitian $\mathrm{H}_{3}$ terbukti.

Hal ini sejalan dengan teori Kasmir (2016), bahwa lingkungan akan mempengaruhi kinerja karyawan. Selain itu juga sejalan sesuai penelitian dari (Ika Nur Cahyaningrum, 2019), (Josephine \& Harjanti, 2017), (Sihaloho \& Siregar, 2019), (Karina et al., 2020) (Anthoni \& Faisal, 2020) dengan hasil yang membuktikan bahwa kinerja karyawan dipengaruhi oleh lingkungan. Dengan Hasil yang sejalan tersebut maka KSO Pertamina EP-Gunung Kampung Minyak perlu memperhatikan lingkungan kerja dalam perusahaannya agar dapat memberikan pengaruh terhadap meningkatnya kinerja para karyawan.

\section{d. Pengaruh Kompensasi Terhadap Kinerja $\left(\mathbf{H}_{4}\right)$}

Hasil uji t hitung atas variabel kompensasi terlihat dari tabel bernilai 0,465 sedangkan signifikansinya 0, 644 ini artinya t hitung bernilai lebih kecil jika diperbandingkan dengan t tabel yaitu 0,465 < 1,673 sedangkan dari sisi signifikansinya $0,644>0,100$ yang menandakan variabel dari faktor kompensasi tidak berpengaruh atas kinerja karyawan hipotesisnya $\mathrm{H}_{0}$ diterima $\mathrm{H}_{\mathrm{a}}$ ditolak dengan demikian hipotesis penelitian $\mathrm{H}_{4}$ ditolak.

Hasil penelitian ini tidak sejalan dengan teori menuruti Zami dalam (Busro, 2018) yang mengatakan jumlah dan komposisi dari kompensasi yang diberikan merupakan faktor yang mempengaruhi kinerja karyawan.

Hasil penelitian ini juga tidak sejalan dengan penelitian yang dilakukan oleh (Zuriana \& Rananda, 2019), (Murtiyoko, 2019) dengan hasil yang membuktikan bahwa kompensasi mempunyai pengaruh positif serta signifikan terhadap variabel kinerja karyawan. Dengan hasil yang tidak sejalan tersebut menunjukkan bahwa tidak ada pengaruh antara kompensasi terhadap kinerja karyawan dalam penelitian ini. Hal ini menggambarkan bahwa terjadi gap atau ketidaksesuaian antara teori dan penelitian terdahulu apabila dibandingkan dengan penelitian yang dilakukan pada KSO Pertamina EP-Gunung Kampung Minyak. Dengan demikian perusahaan KSO Pertamina EP-Gunung Kampung Minyak untuk meningkatkan kinerja karyawan dapat memperhatikan faktor lainnya dari teori selain teori kasmir (2016) seperti teori Zami dalam (Busro, 2018).

\section{KESIMPULAN}

Penelitian yang dilakukan pada KSO Pertamina EP-Gunung Kampung Minyak menunjukkan bahwa faktor-faktor yang mempengaruhi kinerja dalam hal ini kepuasan kerja, lingkungan kerja dan kompensasi memiliki pengaruhnya terhadap kinerja perusahaa. Sedangkan ketika diuji secara per indikator ada hasilnya menunjukkan bahwa baik kepuasan kerja maupun lingkungan kerja memiliki pengaruhnya terhadap kinerja karyawan, namun yang berbeda terjadi pada faktor kompensasi dimana hasilnya menjelaskan bahwa tidak ada pengaruhnya antara kompensasi kepada kinerja karyawan.

\section{REFERENCES}

A.Hidayat. (2018). PENGARUH KOMPENSASI DAN LINGKUNGAN KERJA TERHADAP KINERJA PEGAWAI DINAS PEKERJAAN UMUM KOTA CILEGON DENGAN KEPUASAN KERJA SEBAGAI VARIABEL INTERVENING. Publik: Jurnal Ekonomi \& Publik, 14(1). https://jurnal.stie-banten.ac.id/index.php/publik/article/view/96

Anthoni, L., \& Faisal, R. (2020). Pengaruh Lingkungan Kerja dan Budaya Kerja Islam Terhadap Kinerja Karyawan PT AJS Amanahjiwa Giri Artha. Keberlanjutan: Jurnal Manajemen Dan Jurnal Akuntansi, 5(1). Daryanto. (2016). Media Pembelajaran. Penerbit Gava Media ,Yogyakarta.

Dr. Kasmir M.M., M. . (2016). Manajemen Sumber Daya Manusia (Teori dan Praktik). In Manajemen Sumber Daya Manusia (Teori dan Praktik).

Fitrianto, I. (2020). Pengaruh Motivasi, Disiplin dan Kepuasan Kerja Terhadap Kinerja Karyawan PT. Bumi Rama Nusantara. Jurnal Mirai Management, 3(1).

Hasanuddin, H., Surati, S., \& Ramly, A. T. (2020). Pengaruh Budaya Organisasi, Kompensasi, Dan lingkungan Kerja Terhadap Kinerja Pegawai Dengan Kepuasaan Kerja Sebagai Variabel Intervening (Kantor Bappeda Kabupaten Bima NTB). Jurnal Manajemen, 11(2). https://doi.org/10.32832/jm-uika.v11i2.3365

Hasibuan, S.P, M. (2018). Manajemen Sumber Daya Manusia. In Bumi Aksara Jakarta.

Ika Nur Cahyaningrum, A. B. (2019). PENGARUH KOMPENSASI DAN LINGKUNGAN KERJA TERHADAP KINERJA KARYAWAN MELALUI KEPUASAN KERJA SEBAGAI VARIABEL INTERVENING (STUDI PADA KARYAWAN PT. SAMPURNA KUNINGAN JUWANA, DI KABUPATEN PATI). Jurnal Ilmu Administrasi Bisnis, 8(3). https://ejournal3.undip.ac.id/index.php/jiab/article/view/24025

Josephine, A., \& Harjanti, D. (2017). Pengaruh Lingkungan Kerja terhadap Kinerja Karyawan pada Bagian Produksi melalui Motivasi Kerja sebagai Variabel Intervening pada PT. Trio Corporate Plastic (Tricopla). Jurnal AGORA, 5(3).

Karina, V., Gadzali, S. S., \& Budiarti, I. (2020). PENGARUH LINGKUNGAN KERJA TERHADAP KINERJA KARYAWAN PADA PT. HADE DINAMIS SEJAHTERA. The World of Business Administration Journal. https://doi.org/10.37950/wbaj.v2i1.916

Muhammad Busro. (2018). Teori-teori Manajemen Sumber Daya Manusia. Prenadamedia Group.

Murtiyoko, H. (2019). PENGARUH KOMPENSASI DAN MOTIVASI KERJA TERHADAP KINERJA KARYAWAN (Studi Kasus di PT. Lautan Otsuka Chemical). JIMF (Jurnal Ilmiah Manajemen Forkamma), 2(1). https://doi.org/10.32493/frkm.v2i1.3417

Sedarmayanti. (2017). Bedah Buku Perencanaan dan Pengembangan Sumber Daya Manusia. In Perencanaan dan Pengembangan Sumber Daya Manusia.

Sihaloho, R. D., \& Siregar, H. (2019). Pengaruh Lingkungan Kerja Terhadap Kinerja Karyawan pada PT Super Setia Sagita Medan. Jurnal Ilmiah Socio Secretum, 9(2).

Tjiong Fei Lie, H. S. (2018). Pengaruh Kepuasan Kerja Terhadap Kinerja Karyawan Melalui Motivasi Kerja pada CV. Union Event Planner. Agora, 6(1).

Wijaya, I. K. (2018). Pengaruh Kepuasan Kerja Terhadap Kinerja Karyawan Cv Bukit Sanomas. Agora, 6(2). 
Ekonomi, Keuangan, Investasi dan Syariah (EKUITAS)

Vol 3, No 2, November 2021, Hal 90-96

ISSN 2685-869X (media online)

DOI 10.47065/ekuitas.v3i2.1074

Zuriana, Z., \& Rananda, A. (2019). PENGARUH KOMPENSASI TERHADAP KINERJA KARYAWAN. Education Journal : Journal Educational Research and Development, 3(1). https://doi.org/10.31537/ej.v3i1.142 